\section{Volkswagen and the road to Paris}

In the wake of the Volkswagen emissions-testing scandal (see Nature http://doi.org/723; 2015), this month's climate summit in Paris needs to roll out an international framework for regulating emissions - with strong incentives and tough penalties. Voluntary national measures are no longer enough.

Volkswagen's gaming of emissions testing underscores the urgency of reinventing transport. Governments must implement electric transport systems and plan for combustion-free inner cities, by expanding such schemes as London's ultralowemission zone, due in 2020. Chancellor Angela Merkel could fast-track zero-emission zones for Berlin, Hamburg, Munich and Frankfurt by 2025, for example - restoring Germany's environmental lead.

The Volkswagen debacle should be treated as an Enron moment for sustainability measurement and valuation, with a comparable overhaul of the requirements for corporate accounting and evaluation. Programmes such as the Redefining Value initiative of the World Business Council for Sustainable Development can capture environmental externalities, including impacts on climate, biodiversity and health. Now we just need governments to incorporate these into their regulatory and stock-market requirements. Gail Whiteman, Harry Hoster Lancaster University, UK. g.whiteman@lancaster.ac.uk

\section{DEFRA responds to badger-cull critique}

In calculating the effectiveness of the latest UK badger-culling targets for controlling bovine tuberculosis, Christl Donnelly and Rosie Woodroffe do not consider the uncertainties in estimating badger populations or how information collected during culling is used to evaluate the success of culls in real time (Nature 526, 640; 2015).

Experience shows that there is greater uncertainty associated with badger population estimates than previously thought. A post-cull assessment by the Department for Environment, Food and Rural Affairs (DEFRA), using the number of badgers removed and reductions in sett occupancy, suggests that badger abundance may have been overestimated. Using the mean of the population estimate to establish a minimum number to be culled, as implied in Donnelly and Woodroffe's calculations, leads to a high probability of a culling objective that could greatly exceed actual badger numbers.

The current culls use methods similar to a trial that ran from 1998 to 2006 in southwest England and the west Midlands. The trial achieved a roughly $70 \%$ reduction in badgers, with large variance between trial zones, based on post-hoc assessments. Applying similar culling effort to a zone should converge on a similar outcome to the trial.

To reduce the badger population by a similar proportion as in the trial while providing an achievable objective, the government has set an initial minimum culling number at the lower end of the estimated population range. Information gathered during the cull will be used to assess whether this number should be increased. The most up-to-date data about the badger population are used to assess whether the culls are removing enough badgers and are therefore likely to achieve a similar outcome to the trial.

Comparison with control zones, where there has been no culling, provides no indication that culling has increased disease in cattle, as was widely predicted in advance of the culls (see go.nature.com/grk4ri). Ian L. Boyd University of St Andrews, UK; and DEFRA, UK. ilb@st-andrews.ac.uk

\section{China emissions: stop subsidizing emitters}

China needs to resolve its conflicting policies on reducing carbon emissions and on increasing economic growth if it is to implement a cap-and-trade system successfully (see Nature 526, 13-14; 2015).

For example, the government subsidizes several industries that are big energy consumers and generate excessive emissions and pollution. China's coal-driven iron and steel industry is one such case, despite its overcapacity, low profit and vicious competition.

By June 2015, six months after China's revised Environmental Protection Law came into effect, 2,556 listed companies were in receipt of government subsidies that totalled 250 times more than the fines for environmental damage (see go.nature.com/ ozprpc (in Chinese) and D. Liu Nature 525, 321; 2015).

These absurd subsidies hamper the transformation of industry to cleaner production and distort resource allocation through local protectionism and lobbying. They should be backed by firmer legislation or abolished.

Xin Miao Harbin Institute of Technology, Harbin, China. xin.miao@aliyun.com

\section{China emissions: alter energy markets}

China has issued a nationwide cap-and-trade programme and a series of laws to cut its carbon emissions by $40-45 \%$ between 2005 and 2020 (see Nature 526, 13-14; 2015 and G. Wagner et al. Nature 525, 27-29; 2015). The realities of running such complicated systems and pricing schemes are daunting, however.

Obstacles include promotion of local government officials, which depends not on how well they protect the environment but on how they help to develop the economy. And more commercial incentives are needed for China to implement ways to reduce emissions.

Although the government has vowed to make the energy sector more accountable in market terms, administrative interventions continue to be the norm. The energy market is dominated by monopolies, and prices are tightly controlled by the administration. These problems must be addressed if China is to use its resources efficiently. Dayuan Li, Shenggang Ren Business School of Central South University, Hunan, China. Xiaohong Chen Hunan University of Commerce, China. bigolee@163.com

\section{Europe's first ' $3 R s$ ' governmental centre}

In September, the German government opened a nationwide centre at the Federal Institute for Risk Assessment that is legally committed to protecting animals used for scientific purposes. The initiative is the first of its kind in Europe and is scientifically independent of executive and political advisory bodies. It aims to encourage greater transparency and raise standards of animal welfare by adopting an interdisciplinary approach.

Known as Bf3R (www.bf3r.de), it will encourage European research to meet the '3Rs' targets for animal experimentation (for replacement, reduction and refinement; see go.nature.com/ yidbm2). It will lead the way in enforcing the country's Animal Welfare Act and European Directive 2010/63/EU on the protection of lab animals.

Bf3R will also advise on legal and other requirements, helping authorities and researchers across Europe to communicate proper animal-protection practice to other scientists and to the public. Gilbert Schönfelder Federal Institute for Risk Assessment (BfR); and Charité - University Medicine Berlin, Germany. Barbara Grune, Andreas Hensel BfR, Germany. gilbert.schoenfelder@bfr.bund.de 